\title{
Correction to: The long-term rate of change in lung function in urban professional firefighters: a systematic review
}

Flynn Slattery ${ }^{1 *}$, Kylie Johnston ${ }^{2}$, Catherine Paquet ${ }^{3}$, Hunter Bennett $^{1}$ and Alan Crockett $^{1}$

\section{Correction to: BMC Pulm Med \\ https://doi.org/10.1186/s12890-018-0711-8}

Following publication of the original article [1], the authors flagged an error in Table 2; specifically, within the row beginning 'Aldrich et al. 2013' on page 11 of the article PDF.

The error in this row is under the column ' $\mathrm{mL} / \mathrm{yr}$ ', and the error reads:

$$
\begin{aligned}
& -344.8[\mathrm{CI},-347.3 \text { to }-342.3]^{\mathrm{i}} \\
& -337.6[\mathrm{CI},-340.4 \text { to }-334.8] \\
& -336[\mathrm{CI},-341 \text { to }-332]
\end{aligned}
$$

Please be advised that this data should read:

$-44.8[\mathrm{CI},-47.3 \text { to }-42.3]^{\mathrm{i}}$

$-37.6[\mathrm{CI},-40.4$ to -34.8$]$

-36 [CI, -41 to -32$]$

\section{Author details}

${ }^{1}$ Alliance for Research in Exercise, Nutrition and Activity, Sansom Institute for Health Research, School of Health Sciences, Universitiy of South Australia, Adelaide, Australia. ${ }^{2}$ School of Health Sciences, Sansom Institute for Health Research, University of South Australia, Adelaide, Australia. ${ }^{3}$ Centre for Population Health Research, Sansom Institute for Health Research, School of Health Sciences, University of South Australia, Adelaide, Australia.

Published online: 06 May 2019

\section{Reference}

1. Slattery, et al. The long-term rate of change in lung function in urban professional firefighters: a systematic review. BMC Pulm Med. 2018;18:149. https://doi.org/10.1186/s12890-018-0711-8,

\footnotetext{
* Correspondence: flynn.slattery@mymail.unisa.edu.au

${ }^{1}$ Alliance for Research in Exercise, Nutrition and Activity, Sansom Institute for Health Research, School of Health Sciences, Universitiy of South Australia, Adelaide, Australia

Full list of author information is available at the end of the article
}

(c) The Author(s). 2019 Open Access This article is distributed under the terms of the Creative Commons Attribution 4.0 International License (http://creativecommons.org/licenses/by/4.0/), which permits unrestricted use, distribution, and reproduction in any medium, provided you give appropriate credit to the original author(s) and the source, provide a link to the Creative Commons license, and indicate if changes were made. The Creative Commons Public Domain Dedication waiver (http://creativecommons.org/publicdomain/zero/1.0/) applies to the data made available in this article, unless otherwise stated. 